\section{LAS CARRERAS PROFESIONALES DE LAS PRIMERAS UNIVERSITARIAS ESPAÑOLAS (1910-1936)}

\author{
Mercedes Montero \\ Universidad de Navarra \\ mmontero@unav.es
}

\section{THE CAREERS OF THE FIRST WOMEN UNIVERSITY GRADUATES IN SPAIN (1910-1936)}

Cómo citar este artículo/Citation: Montero, M. (2016). "Las carreras profesionales de las primeras universitarias españolas (1910-1936)". Arbor, 192 (778): a298. doi: http:// dx.doi.org/10.3989/arbor.2016.778n2001
Copyright: (c) 2016 CSIC. Este es un artículo de acceso abierto distribuido bajo los términos de la licencia Creative Commons Attribution (CC BY) España 3.0.
RESUMEN: El artículo está centrado en la presencia progresiva de la mujer española en el mundo profesional, como consecuencia del libre acceso a la Universidad (1910). Metodológicamente es un estudio historiográfico que compara las distintas tendencias en la literatura científica generada sobre el tema. Los resultados apuntan a la existencia de dos momentos importantes. En el primero (años 20), las mujeres trabajaron en especialidades médicas (preferentemente ginecología, pediatría u oftalmología) y empezaron a ganar oposiciones tanto para el cuerpo oficial de Archivos y Bibliotecas como para los institutos de enseñanza media. En el segundo (años 30), las mujeres alcanzaron la investigación científica, y el ejercicio profesional del periodismo, el derecho y la política. La discusión científica está en cómo se alcanzaron estas metas en el contexto social, político y cultural de aquellos años, concluyendo que se debió al propio empuje de las mujeres, apoyadas por corrientes sociales ajenas al feminismo.

PALABRAS CLAVE: Mujeres; universidad; profesión; España; 1910-1936.
ABSTRACT: The article focuses on the increasing presence of Spanish women in the professional world as a result of free access to the University (1910). Methodologically, it is a historiographical study comparing the different trends in the scientific literature on the subject. The results explain the existence of two important moments in time. In the first (20s), women worked in medical specialties (preferably gynecology, pediatrics or ophthalmology) and began to hold posts in the public sector: in archives, libraries and high schools. In the second (30s), women managed to work in scientific research and the professional practice of journalism, law and politics. The scientific debate centers on how these goals were achieved in the social, political and cultural context of those years, concluding that it was a result of the women's own efforts with support from social trends outside feminism.

KEYWORDS: Women; University; work; Spain; 1910-1936. 
En 1910 se permitió en España el acceso oficial de las mujeres a la Educación Superior y, como consecuencia, estas estuvieron capacitadas para desarrollar con posterioridad carreras profesionales. Aquellas primeras universitarias vivieron una época convulsa, con el telón de fondo del eterno conflicto entre las dos Españas. Por un lado la liberal laicista, calificada de progresista, culta y abierta. Por otro, la tradicional, que suele presentarse configurada por los cánones morales de la Iglesia, culpable siempre, al parecer, del retraso y la ignorancia de las mujeres.

Desde 1910 hasta la Guerra Civil, ambas tendencias apoyaron los esfuerzos femeninos para la formación intelectual y el desempeño de una profesión. En el campo liberal fue la Institución Libre de Enseñanza, a través de los organismos de la Junta para Ampliación de Estudios (JAE) quien se ocupó de esta tarea. En el ámbito católico fue Pedro Poveda quien percibió esta necesidad, que encauzó a través de la fundación de la Institución Teresiana. Entre las mujeres que desarroIlaron una carrera profesional encontramos un buen número de ellas relacionadas con las instituciones de la Junta para Ampliación de Estudios. Aunque Pedro Poveda apoyó igualmente los afanes profesionales de las mujeres, tanto él como la Institución Teresiana trabajaron en gran medida con el sector del magisterio, aunque no exclusivamente. Este hecho es la causa de que no aparezcan en el presente artículo demasiadas mujeres profesionales vinculadas al ámbito católico, aunque sí hubo muchas jóvenes universitarias. E incluso la Residencia para chicas estudiantes, fundada por la Institución Teresiana en 1914, es anterior a la Residencia de Señoritas, emanada con el mismo fin, por parte de la JAE en 1915.

No todas las mujeres profesionales que se formaron en el ámbito de las instituciones de la JAE fueron contrarias al sentido religioso católico. Por el contrario, muchas de ellas se consideraron siempre creyentes y de modo especial algunas de las más visibles.

Es necesario afirmar que fue el esfuerzo y la voluntad de las propias mujeres el motor principal de su presencia en la Universidad y en las profesiones. Las iniciativas que hemos mencionado solo apoyaron un impulso que ya existía. Es más: tanto en el ámbito institucional como en el católico fueron multitud los que vieron con prevención y prejuicios notables este lento avance femenino desde el espacio privado hacia la presencia pública. En el mundo católico, la pretensión de Poveda de "educar señoritas" no dejaba de verse como una excentricidad y acaso como un serio peligro, pues estaba muy extendida la idea de que la cien- cia destruía la piedad y alejaba a las mujeres de Dios. Por parte de la Residencia de Señoritas, el principal organismo de apoyo a la mujer universitaria emanado de la JAE, hay que decir que contó siempre con recursos materiales inferiores a la Residencia de varones y que, en buena medida, ocupó de costumbre un lugar secundario en el organismo general. Por ejemplo, Madame Curie se alojó en la Residencia de Señoritas durante su visita a España, pero únicamente expuso su saber en la Residencia de Estudiantes.

No existió en España por aquellos años un movimiento feminista propiamente dicho; teniendo en cuenta además que, en esos momentos, tal fenómeno se hallaba circunscrito a las corrientes sufragistas y de igualdad con el varón en el acceso al trabajo. Faltaban todavía muchos años para que Simone de Beauvoir escribiera El segundo sexo. Evidentemente hubo en España mujeres que se declararon desde muy temprano partidarias del voto femenino. Pero aquello no fue una corriente masiva, tal como lo entenderíamos hoy. De hecho, el agrio debate que se produjo a raíz de la aprobación de este derecho, en plena República y entre los grupos izquierdistas, es una muestra llamativa de lo que venimos diciendo.

Sí hubo un contado grupo de mujeres con carrera universitaria y carrera profesional que fundaron algunas asociaciones femeninas con el objetivo de relacionarse con otras similares de carácter internacional. Estas mujeres fueron Elena Soriano (médico), María de Maeztu (directora de la Residencia de Señoritas), Clara Campoamor y Victoria Kent (ambas abogadas). Así, en 1920 nació en Madrid la Juventud Universitaria Femenina (JUF), que solo admitía graduadas y que se adscribió ese mismo años a la FIMU (Federación Internacional de Mujeres Universitarias). En enero de 1921 se creó otra asociación, derivada de la JUF: la Federación Española de Mujeres Universitarias, para chicas que aún estaban estudiando. Ni una ni otra contaron con demasiadas socias, ya que eran pocas las universitarias en los años veinte y además no tenían especial interés en relacionarse con estudiantes de otras naciones. Tampoco la sección española tuvo peso específico en la FIMU: en 1928 había 68 afiliadas de nuestro país sobre un total de 48.568 .

En el ámbito nacional estas asociaciones llevaron a cabo acciones interesantes pero sin excesiva continuidad y cuya incidencia real apenas se conoce: campañas orientadas a la mejora de las condiciones higiénico-sanitarias de mujeres y niños y al conocimiento de sus derechos jurídicos, conferencias en la Universidad y el Ateneo, concesión de becas a 
muchachas para el pago de las matrículas universitarias, oficina de trabajo para ayudar a las licenciadas a ejercer sus carreras y también oficina de empleo para mujeres de las clases populares (Maillard, 1990, pp. 11-31). No parece que el asociacionismo femenino en este ámbito concreto resultara una ayuda decisiva para la conquista del espacio público.

El presente artículo está centrado en el estudio de las carreras profesionales más notables que desarrollaron las mujeres en España a partir de su formación universitaria. Metodológicamente es un trabajo de historiografía donde se estudia, se compara y se obtienen conclusiones a partir de la literatura publicada sobre el tema.

\section{AÑOS VEINTE: LENTO CRECIMIENTO EN LAS AU- LAS, PRESENCIA TESTIMONIAL EN LAS PROFESIONES}

Hasta comienzos de los años veinte no hubo en España cifras oficiales sobre el número de mujeres matriculadas en la Universidad. En el curso académico 1919-1920 eran 345 alumnas. Diez años después el número ya ascendía a 1.744 .

La tabla I ofrece datos de los cursos 1919-20 y 1927-28.

Tabla I. Evolución del número total de matrículas femeninas por Universidades (1919-1928)

\begin{tabular}{lcc}
\hline UNIVERSIDAD & 1919-1920 & 1927-1928 \\
\hline Barcelona & 54 & 229 \\
\hline Granada & 24 & 124 \\
\hline La Laguna & - & 14 \\
\hline Madrid & 174 & 799 \\
\hline Murcia & 11 & 20 \\
\hline Oviedo & 4 & 31 \\
\hline Salamanca & 10 & 70 \\
\hline Santiago de C. & 10 & 116 \\
\hline Sevilla & 13 & 46 \\
\hline Valencia & 18 & 53 \\
\hline Valladolid & 14 & 56 \\
\hline Zaragoza & 13 & 123 \\
\hline Fuente: Capel Martínez, 1982, p. 469. &
\end{tabular}

Fuente: Capel Martínez, 1982, p. 469.

Sin embargo, a pesar del evidente avance, comparando la presencia femenina en la Universidad con la de los hombres, resulta evidente el largo camino que todavía le quedaba por recorrer a la mujer. Lo podemos ver gráficamente en la tabla II.
Tabla II. Varones y mujeres en la Universidad española (1919-1930)

\begin{tabular}{cccccc}
\hline Cursos & $\begin{array}{c}\text { No } \\
\text { varones }\end{array}$ & $\begin{array}{c}\text { No } \\
\text { mujeres }\end{array}$ & Total & $\begin{array}{c}\% \\
\text { varones }\end{array}$ & $\begin{array}{c}\% \\
\text { mujeres }\end{array}$ \\
\hline $1919-20$ & 21.813 & 345 & 22.158 & 98,5 & 1,5 \\
\hline $1929-30$ & 31.813 & 1.744 & 33.557 & 94,8 & 5,2 \\
\hline
\end{tabular}

Fuente: elaboración personal a partir de Capel Martínez, 1982, p. 473; y Barrera Peña y López Peña, 1983, p. 108.

La presencia femenina en las distintas Facultades no estaba muy equilibrada. La mujer española optó en aquellos primeros años por dos carreras fundamentales: Filosofía y Letras, y Farmacia. La primera fue la más solicitada durante algún tiempo porque permitía después desarrollar un trabajo profesional, como era la preparación de oposiciones al cuerpo de Archiveros, Bibliotecarios y Arqueólogos y a cátedras de Instituto. Pero a partir de 1923-1924, Farmacia mantuvo ya siempre el primer lugar.

En la tabla III podemos apreciar la distribución de las alumnas según facultades.

\subsection{Mujeres intelectuales; humanistas; pedagogas y escritoras}

Puesto que los estudios de Filosofía y Letras fueron los preferidos hasta mediados de los años veinte, es razonable que algunas de las carreras profesionales más interesantes del mundo femenino fueran desarrolladas por mujeres que realizaron dichos estudios. Tres personalidades destacaron sobre las demás: María de Maeztu Whitney, María Vicenta Amalia Goyri y María Zambrano.

La primera fue directora de la Residencia de Señoritas (1915-1936), creada por la Junta para Ampliación de Estudios (JAE) con el objetivo de proporcionar un entorno adecuado a las muchachas que querían estudiar una carrera universitaria en Madrid. María de Maeztu (1881-1948) se nos presenta como "la súper mujer del primer tercio del siglo", según la denominó Mangini. Estudió Magisterio y Filosofía y Letras, (con Premio Extraordinario) e incluso comenzó Derecho. Pero renunció a esta carrera porque nunca iban a dejarla ejercer. En declaraciones a Josefina Carabias en Estampa el 24 de junio de 1933, decía:... "la noticia de que yo pensaba vestir la toga se extendió por Bilbao, y el Colegio de Abogados, reunido para examinar tan grave cuestión, acordó cerrarme sus puertas, caso de que yo terminase la carrera, e instar a los otros colegios de España para que hicieran lo mismo. En vista de esto y de otras cosas, desistí de vestir la toga". Re- 
Tabla III. № de mujeres en las distintas carreras universitarias (1919-1920/1929-1930)

\begin{tabular}{lccccc}
\hline Cursos & Derecho & Medicina & Filosofía y L. & Ciencias & Farmacia \\
\hline $1919-20$ & 9 & 58 & 80 & 114 & 81 \\
\hline $1920-21$ & 10 & 75 & 111 & 150 & 112 \\
\hline $1921-22$ & 13 & 96 & 154 & 200 & 149 \\
\hline $1922-23$ & 14 & 106 & 164 & 245 & 207 \\
\hline $1924-25$ & 18 & 131 & 261 & 274 & 350 \\
\hline $1927-28$ & 71 & 166 & 441 & 395 & 596 \\
\hline $1929-30$ & 86 & 199 & 460 & 222 & 777 \\
\hline
\end{tabular}

Fuente: elaboración personal a partir de Vázquez Ramil, 2001, p. 121; Capel Martínez, 1982, p. 473 y Ezquerra, 1926, p. 493.

cibió pensiones de la JAE para estudios de pedagogía y filosofía en 1910 y 1912 . En 1919 ya dictó cursos en la Universidad de Columbia (Nueva York) y en Smith College, donde recibió el nombramiento de Doctora Honoris Causa. En los años veinte, sucesivos viajes la Ilevaron a las Universidades de Chicago, San Francisco y Berkeley, así como a diversos Colleges femeninos americanos. Viajó y pronunció conferencias en Cuba, Argentina, México y Londres. Fue delegada española en importantes congresos internacionales, bien de mujeres universitarias, bien de educación. En fin, pocos hombres podían presentar en aquellos tiempos el currículo profesional de María de Maeztu. Participó también en política durante la Dictadura del general Primo de Rivera, pues aceptó ser miembro de la Asamblea Nacional desde su constitución en 1927. Pero el verdadero tema de su vida no fue la política sino la educación y la emancipación de la mujer. Era de carácter apasionado, entusiasta y también irritable. En 1932 nació la sección de Pedagogía de la Facultad de Filosofía y Letras, de la que fue nombrada auxiliar temporal de Pedagogía. Poco antes de estallar la guerra civil, el 27 de junio de 1936 se le adjudicó la cátedra de Pedagogía porque el titular, Luis de Zulueta, había sido nombrado embajador ante la Santa Sede (Pérez-Villanueva Tovar, 1989, pp. 20-27, 74-89; Jiménez-Landi, 1996, pp. 485-486; López Sánchez, 2006, p. 144; Vázquez Ramil, 2001, pp. 148-151; Mangini, 2001, pp. 80-81).

Capítulo especial merece también María Vicenta Amalia Goyri (1873-1955). En 1891-92 fue admitida como alumna libre oyente de la Facultad de Filosofía y Letras de la Universidad Central. Iba con su amiga Carmen Gallardo y el padre de esta. Al casarse la primera, Goyri decidió seguir en la Universidad y además de modo oficial, cosa que consiguió después de muchas deliberaciones de las autoridades universitarias, pues se temía que pudiera perturbar el orden de las clases. Se estableció un protocolo: "En las aulas estará separada de sus compañeros y tampoco podrá hablar con ellos en los pasillos. Entre clase y clase debe permanecer en la antesala de los profesores. Cuando el bedel anunciara el comienzo de las clases habría de ser acompañada por un catedrático para ocupar en el aula la mesita supletoria a ella destinada" (Mangini, 2001, pp. 52-54). En 1898 empezó a escribir en Revista Popular, donde tuvo una tribuna propia titulada "Crónicas femeninas". En la primera entrega, hablando del trabajo fuera del hogar, decía que lo primero era fomentar la conciencia clara de que no era rebajarse el hecho de prestar un trabajo retribuido. El trabajo siempre dignificaba y había que colocarse en condiciones de no ser una carga. Además, la mujer debía participar en la sociedad en igualdad de condiciones porque su aportación resultaba valiosa (Flecha y Torres, 1998, pp. 147150). En 1900 contrajo matrimonio con Ramón Menéndez Pidal. Colaboró intensamente en los estudios filológicos de su marido. El suyo fue un caso de entrega excepcional, hasta el punto de que nunca sabrá nadie dónde llegó la labor de uno y empezó la de la otra. Se les llamó el matrimonio Curie de las letras españolas. Ella personalmente editó varios libros en solitario pero nunca apareció su firma en los trabajos realizados junto a su marido (Mangini, 2001, pp. 52-54).

Era creyente, pero se recelaba de ella porque no era convencional ni en su vida, ni en su matrimonio. Hasta sus suegros hubieran querido que su hijo se casase con una chica menos moderna. La familia de su marido era muy conservadora y no les gustaba María. El hecho de haber ido a la Universidad con hombres era de un atrevimiento rayano en el escándalo. Además le acusaban de haber influido negativamente en la religiosidad de su hijo. Pero como ya hemos dicho, Goyri era creyente: iba a Misa a las seis de la mañana y nadie en la casa lo advertía. Era absolutamente reservada en sus asuntos espirituales (Rodrigo, 1979, pp. 32-53). 
María Zambrano fue otra universitaria y profesional notable, ligada (como las dos anteriores) a la Institución Libre de Enseñanza. Se licenció en Filosofía y comenzó la tesis doctoral con Ortega y Gasset, aunque nunca llegó a terminarla. Trabajó en el InstitutoEscuela (Ribagorda, 2005, p. 60). Su círculo social fue amplísimo. Trató a la generación del 98 por influencia de su padre, Blas Zambrano, amigo íntimo de Antonio Machado. En la Universidad estableció relaciones con varios de sus profesores, entre ellos Manuel Azaña, Julián Besteiro, García Morente, Zubiri y Ortega y Gasset. Conoció y trató igualmente a León Felipe, García Lorca, Rosa Chacel, Jiménez de Asúa, José Giral, Indalecio Prieto o Valle-Inclán. Fueron sus compañeros de estudios Aurora Riaño, Domingo Díaz Hambrona y Francisco Giral. Ella se convirtió en el puente entre las dos generaciones que se manifiestan en estos nombres. El 23 de junio de 1928 comenzó una tertulia con gentes de ambos grupos en un establecimiento de Madrid Ilamado "La Bombilla". A principios de los años 30 su casa se convirtió en lugar de reunión de los ya citados con otros como Cela, Neruda, Miguel Hernández, Bergamín, Rosales, Maravall, o la pintora Maruja Mallo (Franco, 2007, pp. 66-71). A pesar de ser quizá la más destacada entre los discípulos de Ortega, este nunca la invitó a la tertulia más famosa del momento, la que se celebraba en la redacción de la Revista de Occidente (Marset, 2004, p. 348).

María Moliner es otra mujer que trabajó en los años veinte. Se licenció en la rama de Historia en 1921, en la Universidad de Zaragoza. En 1922, ganó la oposición para el cuerpo de Archiveros, Bibliotecarios y Arqueólogos, desarrollando su labor en el Archivo de Simancas primero y en el de Murcia más tarde. Su inmensa labor en lexicografía quedaría manifiesta años después en el Diccionario de usos del español.

María Sánchez Arbós fue otra Licenciada en Filosofía y Letras, pedagoga de renombre, esposa del institucionista Manuel Ontañón.

Encarnación Aragoneses, más conocida como Elena Fortún, se licenció en Filosofía y Letras en la Universidad de Madrid y se dedicó a la literatura, siendo la famosa autora de los libros de Celia.

Figura de relieve fue también Benita Asas Manterola, que comenzó Filosofía y Letras a los 37 años. Antes había cursado Magisterio. Nacida en 1873, su vida estuvo dedicada a promover la mejora de la condición social, política, jurídica y económica de la mujer. Militó activamente como sufragista. Era católica. Entre 1924 y 1932 presidió la Asociación Nacional de Mujeres Es- pañolas (ANME), que buscaba la unión de las mujeres en un espacio común, un frente que las defendiera de la discriminación a la que estaban sometidas. El franquismo la depuró del cuerpo de maestras (Martínez et al., 2000, pp. 408-412).

Otras, menos conocidas, procedentes también de los estudios de Humanidades, lograron realizar cierta carrera profesional. Entre ellas podemos citar a Luisa Cuesta Gutiérrez, que entre 1918 y 1921 fue auxiliar interino y luego profesor ayudante de la Facultad de Filosofía y Letras de Valladolid, y entre 1924 y 1927 auxiliar de la Facultad del mismo nombre en la Universidad de Santiago de Compostela. Otra licenciada en Filosofía y Letras que alcanzó metas profesionales fue María Luisa García Dorado, que en 1923 ingresó en el escalafón de Catedráticos de Instituto, siendo una de las primeras mujeres en conseguirlo; o Aurea Javierre, doctora con Premio Extraordinario, una competente archivera e investigadora que ganó en 1930 el premio de Historia de la Sociedad Económica Barcelonesa de Amigos del País (Ezquerra, 1926, pp. 492-494; Capel Martínez, 1982, p. 473; Laffitte, 1964, p. 324 y p. 329; Varela, 1989, pp. 185-186; Martínez et al., 2000, pp. 505-507, pp. 565-568 y pp. 598-599; Pérez-Villanueva Tovar, 1990, p. 322; Jiménez-Landi, 1996, pp. 496-498; Rodrigo, 1979, pp. 32-53).

\subsection{De las recetas de cocina a la investigación científica}

A mediados de los años veinte los estudios de Farmacia superaban ya ampliamente a los de Filosofía como primera elección entre las mujeres. En el total de las Universidades españolas, en el curso académico 1922-1923, estaban matriculadas 207 chicas estudiantes de Farmacia. En el curso académico 19271928 eran ya 596 , el $17,6 \%$ del total y el $34,7 \%$ de la matrícula femenina.

Los estudios de Farmacia se consideraban muy apropiados para la mujer, porque regentar una oficina de composición y dispensa de medicamentos era visto como una extensión de sus tareas domésticas habituales. Citando a un autor de la época, dice Vázquez Ramil que la Farmacia se consideraba como una forma superior de la cocina, en la que solo era necesario seguir al pie de la letra la "receta", tener paciencia y permanecer en quieta y sosegada reflexión. Nos puede servir de ejemplo de esta mentalidad la trayectoria profesional de Isabel Torres, Licenciada en Farmacia, que fue la única mujer que trabajó en la Casa de Salud de Valdecilla (Santander) ya a finales de la década, en 1929. Su perfil biográfico muestras las características sociales e intelectuales del personal de la Casa de Sa- 
lud: la plasmación del programa de la ILE y la JAE de regeneración del país mediante elites. Isabel Torres se incorporó como alumna interna en el servicio de Química del flamante hospital, pero su sexo condicionó tanto su adscripción laboral como el tipo de investigación que tuvo que realizar. En cuanto a lo primero, fue contratada bajo diversas figuras curiosas: médico externo de guardia, farmacéutica sin salario o personal de Química, pero nunca como interno. Era más fácil sostener una adscripción laboral extraña, que, siendo mujer, asumir ese título. En cuanto a lo segundo, el sexo condicionó igualmente la investigación: la comida era asunto de señoras. Ella no tuvo interés intelectual en la valoración nutricional de los alimentos hospitalarios, pero aquello constituía un querer esencial de la clínica. De hecho, se utilizó decididamente en la creación de su peculiar imagen. La Casa de Salud de Valdecilla supuso una experiencia piloto de moderno hospital en España. Quería alimentar a sus pacientes según métodos científicos, siguiendo una línea ya comenzada en Estados Unidos y Canadá (Ezquerra, 1926, p. 492; Capel Martínez, 1982, p. 473; Vázquez Ramil, 2001, p. 121; Segura Graiño, 1997, pp. 44-51).

Otras licenciadas en Farmacia con cierta proyección investigadora fueron María Josefa Barba Gose, Rosa Herrera, Carmen Pradel y Trinidad Salinas. La primera ganó una pensión de la JAE en 1928 para estudiar Farmacología y valoraciones farmacológicas en Inglaterra. Rosa Herrera fue directora del Laboratorio Foster, de la Residencia de Señoritas, entre 1923 y 1925. En 1929 obtuvo una beca de la JAE para ampliar estudios de Química en Inglaterra, Francia y Suiza. Además de Licenciada en Farmacia lo era también en Ciencias Naturales. Carmen Pradel trabajaba ya en 1921 en la Sección de Físico-Química del Laboratorio de Investigaciones Científicas (Instituto Nacional de Ciencias), dedicada a la revisión de pesos atómicos. Trinidad Salinas realizó su doctorado en Farmacia a partir de 1928, investigando sobre el flúor en plantas y animales, en el Laboratorio de Análisis Químicos de la Facultad de Farmacia (Magallón Portolés, 1999, pp. 121-213, p. 215, p. 217 , p. 295, p. 308 , pp. $324-325$, p. 337).

También se dedicaron a la investigación científica mujeres procedentes de la carrera de Ciencias. Se conoce la identidad y contribuciones de 17 mujeres que estuvieron presentes en los laboratorios del Instituto Nacional de Ciencias durante la década de los veinte. Así, en el Laboratorio de Investigaciones Físicas, en el área de Rayos X y estructura de cristales nos encontramos con Felisa Martín Bravo y Pilar Álvarez-Uder; en Electroquímica y Electro-análisis con Teresa Salazar,
Francisca Lorente y Carmen García Amo. En el Laboratorio de Análisis Químico de la Facultad de Farmacia investigaron Carmen Miguel, Ascensión Vidal, María Luz Navarro, Mercedes Loperena, y Carmen y María de los Desamparados Brugger. Y por último, en el Laboratorio de Química Orgánica y Biología desarrollaron sus trabajos Concepción Espeso, Carmen Gómez Escolar y Natividad Gómez.

Destaca entre todas Felisa Martín Bravo, primera doctora española en Ciencias Físicas en 1926, que seguiría desarrollando en los años 30 una sólida carrera profesional, con becas en el extranjero y docencia en la Universidad Central. La misma trayectoria (estancias en otros países, profesor auxiliar en la Universidad) siguió Teresa Salazar. Carmen Gómez Escolar continuó igualmente con sus investigaciones hasta 1936.

Jenara Vicenta Arnal, hija de jornalero y de ama de casa, es otro buen ejemplo de la valía profesional de estas mujeres universitarias de los años veinte. En 1921 logró el título de maestra de primera enseñanza. En 1923 el de bachillerato. En 1926 era licenciada en Química por la Universidad de Zaragoza. Accedió tempranamente a la docencia superior, pues en 1927-28 la encontramos en esa misma Universidad como ayudante de prácticas, y el curso siguiente como ayudante temporal de Electroquímica. Este trabajo lo compaginó con la preparación de oposiciones a cátedra de instituto, ganadas en 1928, y con la realización de su tesis doctoral, defendida en 1929, por la que obtuvo además premio extraordinario.

La primera licenciada y doctora en Matemáticas fue Carmen Martín Sancho. En 1924 consiguió la licenciatura y en 1927 el doctorado, con premio extraordinario. Hizo oposiciones a cátedra de instituto y ejerció primero en El Ferrol (1928) y después en el Infanta Beatriz de Madrid (1929). En 1931 recibiría una pensión de la JAE para realizar estudios de geometría multidimensional en Berlín.

María Dolores Ferrer Sensat, licenciada en Ciencias por la Universidad de Barcelona, también fue en 1929 profesora auxiliar de esa Facultad.

Margarida Comas i Camps se licenció en Ciencias en 1925, también en la Universidad de Barcelona. Era de origen mallorquín, y su padre estuvo ligado a la ILE. En 1911 consiguió su título de maestra de primera enseñanza y en 1912-15 estudió en la Escuela Superior de Estudios del Magisterio, en Madrid. En 1920, gracias una pensión de la JAE, amplió estudios en Inglaterra, en el Belford College for Women de la Universidad de Londres. En 1926, después de su licenciatura consi- 
guió otra beca de la JAE para estudiar en la Sorbona, de cara a realizar su tesis doctoral. En los años $30 \mathrm{se}$ introdujo en temas de pedagogía sexual. Fue admiradora y seguidora de los principios de la 'Escuela Nueva' inglesa y colaboradora de Revista de Educación. Tras la guerra se exilió en Inglaterra.

Por último, cabe destacar el caso de Dorotea Barnés, una de las cuatro hijas del que sería ministro de Educación de la Segunda República, Domingo Barnés. Todas fueron universitarias. Dorotea estudió su carrera durante los años veinte. En 1928 fue admitida como miembro de la Real Academia de Española de Física y Química. En 1929 pasó un año en el Smith College, con una beca de intercambio, completada por una pensión de la JAE. Al año siguiente consiguió la beca "Marion Le Roy Burton" para trabajar en el Departamento de Química de la Universidad de Yale. La distinción era ya en sí algo de bastante envergadura, pero mucho más tratándose de una mujer (Ezquerra, 1926, p. 492; Magallón Portolés, 1999, p. 129, p. 134, p. 137, pp. 213217 , p. 219 , pp. $223-235$, pp. 278-290, p. 297, p. 307, p. 329, p. 337; Capel Martínez, 1982, p. 473).

\subsection{Pediatras, oftalmólogas y médicas en la marina mercante}

Muy por detrás en las preferencias femeninas quedaba Medicina. En 1922-1923 estudiaban esta carrera en España un total de 106 chicas. Precisamente había sido Medicina la carrera cursada en el siglo XIX por las pioneras españolas. La primera universitaria (María Dolores Maseras) realizó estos estudios, y la primera doctora (Martina Castells) lo fue también en esa ciencia. Sin embargo, con el paso de los años, el número de mujeres interesadas en la Medicina fue decayendo. El motivo de este relativo abandono pudo estar en el estrecho margen profesional que le quedaba a la mujer médico: casi únicamente Ginecología, Obstetricia, Pediatría y Oftalmología. Otras especialidades como la Cirugía no parecían aptas para la sensibilidad femenina.

Hubo en España, a pesar de todo, algunas mujeres médicas de relieve en los años veinte. Nos encontramos, en primer lugar, con Concepción Aleixandre Ballester, doctora del Hospital de la Princesa en Madrid y activa profesional desde principios de siglo. Fue miembro de la Asociación Española para el Progreso de las Ciencias en 1912 y ponente en 1913 de un trabajo sobre "La lactancia materna y la tuberculosis" en el segundo congreso internacional sobre este tema, celebrado en nuestro país. Trinidad Arroyo logró ser médico del cuerpo facultativo del Consultorio de Niños de Pecho, en oftalmología. Cecilia García de la Cosa fue una de las primeras médicos por oposición de la Marina Mercante Española. Ya antes, entre 1923 y 1926 había sido nombrada alumna interna numeraria de la Facultad de Medicina de la Universidad de Sevilla.

La otra mujer médico que ganó la misma oposición de la Marina Mercante, en 1928, fue Elena Soriano Fisher. Maestra y oftalmóloga, Soriano fue huérfana de madre desde la infancia y la educó su padre, el ginecólogo Soriano Surroca. Con él acudía a las visitas médicas y a los congresos. Fue la tercera mujer que estudió Medicina en la Universidad de Madrid y además realizó el doctorado. Se especializó en oftalmología que era entonces una rama muy feminizada. Ejerció desde 1923 en el Instituto de Oftalmología de la Beneficencia. Fue además la primera mujer profesor clínico del Hospital de San Carlos en Madrid. Estuvo vinculada a organizaciones higiénicas y sociales, publicó numerosos artículos y denunció la situación discriminatoria que sufrían las mujeres médicos. Elena Soriano tuvo un papel muy activo en el movimiento universitario femenino internacional y en la vida pública española durante los años veinte. En este sentido, organizó en España el XII Congreso de la International of Women University (13-25 de septiembre de 1928) Participó igualmente en política, formando parte del Partido Radical en un momento incierto de su vida, además de haber pertenecido antes a la Unión Patriótica del general Primo de Rivera. Fue también sufragista convencida, miembro de la Asociación Nacional de Mujeres Españolas (ANME) e impulsora y secretaria de la Asociación de Médicas Españolas, fundada en Madrid en 1928 con quince mujeres.

Podemos citar también a la doctora barcelonesa María Luisa Quadras Bordes, primera radióloga española, una especialidad que se sale de las habituales entre las mujeres (Ezquerra, 1926, pp. 492-493; Capel Martínez, 1982, pp. 469-480; Magallón Portolés, 1999, p. 303 y p. 317; Húder y Lasala, 1913, p. 13; Pérez-Villanueva Tovar, 1990, p. 323; Martínez et al., 2000, pp. 689-690).

Por su parte, Marina García Escalera, también licenciada en Medicina, llegó a ser Inspectora Nacional de Sanidad y contribuyó decisivamente a la fundación de la Escuela Nacional de Puericultura. Ejerció como ginecóloga en la organización sanitaria pública. Había sido becaria de la Residencia de Señoritas en los años 20, durante sus estudios en la Universidad (Pérez-Villanueva Tovar, 1990, p. 323). Juana García Orcoyen fue la primera licenciada navarra en Medicina, carrera que estudió en los años veinte y que posteriormente 
ejerció junto a su marido, médico también, director del Sanatorio Marítimo de Malvarrosa (Valencia) (Diario de Navarra, 7 de enero de 2007, p. 49).

\subsection{El ejercicio privado de la abogacía}

La carrera de Derecho se hallaba en el último lugar de las preferencias femeninas. No era extraño. Se trataba de unos estudios que capacitaban para un conjunto de profesiones prohibidas por ley a la mujer, pues no podía presentarse a las oposiciones a Judicaturas, Notarías, Registros de la Propiedad y Abogados del Estado. Por otra parte, era la carrera que abría las puertas a la vida política, y la mujer no tuvo pleno derecho al voto hasta 1931. Evidentemente, el número de estudiantes era muy reducido, puesto que les quedaba el ejercicio privado de la profesión o la dedicación al periodismo. Así, no resulta extraño comprobar que tan solo 18 alumnas, en todo el país, estudiaban esa carrera. Casi al final de la década, en el curso 1927-1928 había ya 81 mujeres cursando Derecho, pero no pasaban de ser el $0,6 \%$ del total de estudiantes de Leyes en España, y el 4,4\% de la matrícula femenina.

Aunque fueron pocas, algunas de estas licenciadas en Derecho jugarían un papel destacado en la vida política española, ya en la Segunda República. Victoria Kent Siano logró convertirse en la primera licenciada en Derecho y, sucesivamente, en la primera mujer que se colegió y en la primera que abrió un bufete en Madrid. En mayo de 1925 tuvo su primer juicio. Clara Campoamor Rodríguez obtuvo su título en diciembre de 1924, cuando contaba ya 36 años de edad, y se colegió, abrió bufete y empezó a ejercer la abogacía casi a la par que Victoria Kent. Fue la segunda mujer en ingresar en la Academia de Jurisprudencia y Legislación (la primera había sido Concepción Peña). Durante los años 20 participó activamente en la vida pública, formando parte de las juntas directivas de numerosas asociaciones de mujeres universitarias, intelectuales y juristas. También participó en congresos internacionales de universitarias. Tanto Clara Campoamor como Victoria Kent pudieron dedicarse al ejercicio privado del derecho porque su trabajo profesional habitual era otro y podían vivir de él. En el caso de Kent, entre 1921 y 1927 formó parte del personal administrativo del Instituto-Escuela de la Institución Libre de Enseñanza, ocupando el cargo de Secretaria General del centro. Campoamor era funcionaria por oposición, desde hacía años, del Ministerio de Instrucción Pública, además de colaborar habitualmente con periódicos como La Tribuna, Nuevo Heraldo, El Sol y El Tiempo.

En el bufete de Clara Campoamor trabajó otra mujer abogada, Justina Ruiz Malaxechevarría. Casada con el médico Manuel Conde, se exilió a los Estados Unidos después de la guerra civil. Obtuvo un doctorado en Harvard y se dedicó a la docencia en literatura.

Matilde Huici Navaz fue la tercera licenciada en Derecho de España, después de Kent y Campoamor. Participó activamente en pro de los derechos de la mujer, y ello la condujo a estar presente en numerosas conferencias, actos culturales y de propaganda organizados por los grupos de izquierdas, como Mujeres Socialistas. También trabajó en la Sección Preparatoria del Instituto-Escuela durante los años veinte, lo que quizá le permitió, como a las dos anteriores, poder ejercer su carrera de Derecho. Perteneció a la Real Academia de Jurisprudencia y Legislación.

Por último debemos citar a Carmen Cuesta del Muro, directora de la Residencia universitaria de la Institución Teresiana. Se mostró activa partidaria de otorgar cuanto antes el voto a la mujer, para que esta, desde el Parlamento, estuviera en disposición de acabar con el maltrato jurídico al que se veía sometida. Quizá por ello formó parte de la Asamblea Nacional en la época de Primo de Rivera, al igual que María de Maeztu (Ezquerra, 1926, pp. 492-493; Vázquiz Ramil, 2001, p. 121; Capel Martínez, 1982, pp. 469-480, pp. 519-520, pp. 566-567; Gutiérrez Vega, 2001, pp. 3339; Fagoaga y Saavedra, 2007, pp. 28-29 y pp. 53-54; Pérez-Villanueva Tovar, 1990, p. 322; Martínez et al., 2000, pp. 486-488; Flecha y Torres, 1993, pp. 119-207)

\section{UNA COMPARACIÓN CON LAS CARRERAS PROFE- SIONALES DE LAS MUJERES NORTEAMERICANAS}

En la década de los veinte la penetración de la mujer en la Universidad era en Europa y Estados Unidos mucho más intensa que en España, como podemos observar en la tabla IV.

Tabla IV. Porcentaje de mujeres universitarias respecto al total de estudiantes

\begin{tabular}{lcccccc}
\hline Cursos & USA & GB & FRANCIA & ALEMANIA & ITALIA & ESPAÑA \\
\hline $1920-21$ & 43 & 24 & 14,7 & 24 & $14,8^{*}$ & 1,2 \\
\hline $1930-31$ & 27 & 25,8 & 27 & & 6,3 \\
\hline "Media de la década & Fuente: elaboración propia. & & & &
\end{tabular}


En los Estados Unidos, además, se había planteado ya un tema radical: la compatibilidad entre trabajo y familia. En la España de los años veinte estas cuestiones sonaban a ciencia ficción, incluso para las mentes más liberales. Pero en los Estados Unidos las propias universidades y las asociaciones femeninas hicieron encuestas y estudios sobre la inserción laboral de las graduadas y las circunstancias ambientales que acompañaban su carrera profesional. En 1926 el Smith College ya había demostrado que sus antiguas alumnas mayoritariamente solían trabajar antes de casarse; que las casadas con carrera profesional no solían tener hijos y que, si los tenían, era entre uno y tres. En general las casadas tenían éxito si su actividad laboral era flexible o la realizaban en casa, de ahí que hubiera un número alto de escritoras, periodistas, pintoras o músicas. De las pocas mujeres científicas que trabajaban, la mayoría lo hacía colaborando con sus maridos.

En 1927, la American Association of University Women (AAUW) trabajó sobre una muestra de 243 graduadas, casadas y profesionales, ex alumnas de tres Colleges: Radcliffe, Boston University y Simmons. La mayor parte de ellas, 231, habían trabajado antes y después de casarse; y aproximadamente un quinto de ellas, 47, lo hacían con su marido. De manera significativa, cerca de la mitad, 139, no tenían niños. Las que eran madres daban una media de 2.1 hijos por mujer.

En 1929 otro estudio de la AAUW demostraba que más de la mitad de las encuestadas, el 58\%, confesaba trabajar por motivos económicos, siendo la vocación profesional un estímulo secundario. Las que habían contraído matrimonio veían más necesario que las solteras poder combinar familia y trabajo, lo cual no sorprende, pues ya había sobrevenido la Gran Depresión y las razones económicas iban a ser las más importantes en los años treinta (Salomon, 1985, pp. 172-185).

Resulta también muy interesante la situación laboral de la mujer científica en los Estados Unidos. No eran muchas y además normalmente trabajaban con sus maridos. Es lo que había hecho Madame Curie, el referente por antonomasia en aquellos momentos. Según Magallón, para la mayoría de los profesores varones el "ejemplo Curie" podía significar que cada mujer que aspirara a ser científica debía alcanzar ese nivel, lo cual no se esperaba que lograra ningún hombre. La misma autora, citando a Rossiter, añade que en la década de los veinte las norteamericanas que deseaban dedicarse a la ciencia, en vez de la confrontación y la protesta pública, utilizaron la llamada 'estrategia Curie', caracterizada por la sobre-cualificación y el estoicismo personal (Magallón Portolés, 1999, p. 117).

\section{ENTRE EL TEMOR MASCULINO Y LA MARGINALIDAD SOCIAL}

En España, en aquellos mismos años, y a pesar de la poca presencia femenina tanto en la Universidad como en las profesiones, se tenía ya cierto miedo a la posible presencia de la mujer en el ámbito público. Tres artículos de investigación, publicados en 1925 por la revista de sociología Renovación Española, dejan entrever esa inquietud incipiente: se temía que la Facultad de Filosofía y Letras, orientadora de la vida cultural, cayera en pocos años en manos de las mujeres. Y se temía quizá porque -según algunos- las universitarias eran voluntariosas y aplicadas, pero en general carecían de esas grandes inteligencias más propias del hombre. La mujer se dedicaba a lo memorístico y ameno, rechazando lo que suponía mayor dificultad especulativa, quizá porque no era muy capaz de generar pensamiento autónomo. Y sin capacidad especulativa ¿cómo se iba a guiar la entera vida cultural de una nación? Además, era otro argumento, la incorporación de la mujer a la vida laboral restaba puestos de trabajo al varón. El autor de estos artículos, Ramón Ezquerra, curiosamente, no era contrario a la educación universitaria de la mujer. Parece que solo estaba poniendo de manifiesto ideas compartidas por buena parte de la sociedad (Ezquerra, 1926; Ezquerra, 1926b; Ezquerra, 1926c).

El problema por excelencia para el trabajo femenino se encontraba, según el autor, en "el factor neutralizador de esfuerzos": el matrimonio. Las chicas se casaban y dejaban de ejercer, si es que en algún momento habían empezado a hacerlo. No habían prestado ninguna atención a su título, dice, y además "este camino (el matrimonio) es el que seguirá la mayor parte, ya que todas tienden a él, manifestándolo más o menos abiertamente [...] esterilizando los resultados que pudieran esperarse [...]". La conclusión era demoledora para las inquietudes profesionales femeninas:

... la mujer no puede eludir el destino biológico que tiene señalado, y que triunfará de las tentativas de apartarlo o desvirtuarlo. Continuará siendo, aun para la mujer erudita, imprescindible su puesto en el hogar, y no podrá ni deberá rechazar las cargas que le impone su papel en la perpetuación de la raza o en la crianza y educación de los hijos, sobre cuya importancia no hay que insistir aquí y que no dejan de ser incompatibles con la atención asidua y persistente al cultivo de una carrera (Ezquerra, 1926c, p. 632).

Está claro que en los años veinte quedaba en España mucho camino que recorrer, mucha mentalidad que abrir, muchos obstáculos que superar para que las 
mujeres pudieran desarrollar, no solo estudios universitarios, sino un trabajo profesional en igualdad con el hombre. Además, con independencia de los prejuicios, existía un dato real y preocupante respecto a la preparación de la mujer para participar en el espacio público y era el analfabetismo femenino: en 1930 el $47,5 \%$ de las españolas no sabía leer ni escribir (Capel Martínez, 1982, p. 370; Garrido, 1997, p. 466).

\section{EL DESARROLLO DE LAS CARRERAS PROFESIONALES FEMENINAS DURANTE LA SEGUNDA REPÚBLICA}

Desde el punto de vista educativo, la República no se centró en promover el acceso de la mujer a la Universidad. Para cualquier gobierno era mucho más urgente y razonable luchar contra las apabullantes cifras de analfabetismo, que dedicar sus esfuerzos al $6 \%$ de la población universitaria. De hecho, en 1931 casi la mitad de las niñas españolas no iban al colegio (Garrido, 1997, p. 499). El nuevo régimen multiplicó los presupuestos del Estado destinados a la educación en todos sus grados y aceleró la creación de escuelas para niñas. De cualquier manera, a pesar del esfuerzo cuantitativo y del aumento real de posibilidades de acceso a los diversos grados de enseñanza, las niñas y adolescentes siguieron recibiendo una educación cuyo contenido se hallaba diferenciado en función de los roles que hombre y mujer iban a jugar en la sociedad. Pese a todo, la aceleración en el bachillerato fue notable: si en 1930-31 el porcentaje de chicas matriculadas en secundaria era de un $17,1 \%$; en $1935-36$ la cifra había crecido hasta el 46,2\% (Merino Hernández, 2003, p. 419, p. 439, pp. 456-457). Todo hace suponer que el fruto de aquel esfuerzo se hubiera recogido en los años 40, en forma de un notable aumento de matrículas femeninas en la Universidad.

De momento, durante la República, la presencia de mujeres en la Universidad creció como indica la tabla V.

Pese a la mejora de la educación secundaria y el relativo aumento de las estudiantes universitarias, el espacio público seguía siendo remiso a la plena igualdad de derechos entre el varón y la mujer. Así lo puso de manifiesto el agrio debate sobre el voto femenino que se desencadenó en España. En las primeras Cortes republicanas (1931-1933) hubo tres mujeres que obtuvieron su acta de diputada: Margarita Nelken, Clara Campoamor y Victoria Kent. Nelken era escritora y Kent y Campoamor, las primeras españolas licenciadas en Derecho. Paradójicamente podían ser elegidas, pero ellas mismas no tenían derecho al voto.

El enfrentamiento por el sufragio femenino entre Kent y Campoamor, probablemente las mujeres profesionales más brillantes de los años treinta, llenó durante unos meses las páginas de los periódicos y podríamos afirmar que toda la vida del país. Ambas eran licenciadas universitarias con una activa vida laboral. Victoria Kent había sido poco antes la primera mujer del mundo que actuó ante un Tribunal Supremo de Guerra y Marina, en la defensa de Álvaro de Albornoz. Además de ganar el juicio, aquello le proporcionó una tremenda popularidad en los primeros meses de la República, llegando hasta a ser motivo de un popular chotis del momento. Poco después del espinoso tema del sufragio femenino, Kent llegaría a convertirse en Directora General de Prisiones, de nuevo la primera mujer en el mundo que ocupaba tal cargo y desde luego la que más alto había llegado -hasta el momentoen la vida política española (Capel Martínez, 1982, pp. 525-529; Gutiérrez Vega, 2001, p. 90).

Por su parte, Campoamor fue delegada de España ante la Sociedad de Naciones entre 1931 y 1933, Directora General de Beneficencia en 1933 y en el ejercicio privado de la abogacía se dedicó en buena medida -a partir de 1932- a causas de divorcio. Llevó dos casos notables de la época: el divorcio de Concha Espina de su marido Ramón de la Serna y Cueto; y el de Josefina Blanco de su marido Ramón María del Valle-Inclán (Capel Martínez, 1982, pp. 519-524; Fagoaga y Saavedra, 2007, p. 39). Victoria Kent y Clara Campoamor militaron en las filas del Partido Republicano Radical Socialista.

Tabla V. Varones y mujeres en la Universidad durante la Segunda República

\begin{tabular}{lccccc}
\hline Curso & No varones & No mujeres & Total & \%varones & \%mujeres \\
\hline $1931-32$ & 31.607 & 2.206 & 33.633 & 94,0 & 6,0 \\
\hline $1932-33$ & 29.858 & 2.047 & 31.905 & 93,7 & 6,3 \\
\hline $1933-34$ & 28.664 & 2.124 & 30.788 & 93.1 & 6,4 \\
\hline $1934-35$ & 31.510 & 2.980 & 34.490 & 91,4 & 8,6 \\
\hline $1935-36$ & 26.661 & 2.588 & 29.249 & 91,2 & 8,8 \\
\hline
\end{tabular}

Fuente: Barrera Peña y López Peña, 1983, pp. 108-109. 
Con independencia de la dureza del debate parlamentario en torno a esta cuestión, lo verdaderamente interesante del tema se halla en la mentalidad que condicionaba la entera discusión: todos daban por hecho el tradicionalismo cultural y religioso de la mujer española. La derecha -convencida de que era así- se congratulaba con ello y se mostraba partidaria del sufragio femenino; la izquierda -compartiendo la misma convicción- se debatía, contradictoria, entre la aceptación teórica del concepto y el miedo ante su realidad en la práctica.

Clara Campoamor defendía el sufragio femenino con rotundidad, aunque existiera la posibilidad de que las mujeres se inclinasen a apoyar a las derechas. Victoria Kent, por su parte, no se oponía al sufragio femenino, pero le parecía mejor aplazar esta concesión porque estaba convencida de que en aquellos momentos suponía un gran peligro para la República. En su opinión, todo el problema residía en la educación. La mujer carecía de la formación adecuada para entender los logros republicanos; le hacía falta recibir una formación especial, era necesario incidir pedagógicamente en ella para que admitiera el nuevo régimen y se encariñase con él. Mientras las escuelas no cumplieran su función -según Kent- las mujeres no podrían intervenir en política con eficacia y con fruto.

Campoamor no tenía -en este caso- la rémora de una educación elitista. Procedente de las clases más humildes, fue modista, dependienta y empleada de telégrafos, antes de opositar a Instrucción Pública, empezar el bachillerato (con 33 años) y continuar con la carrera. Su contacto con la Institución Libre de Enseñanza había sido mucho más ligero que el de Kent. Esta había recibido, por el contrario, una atenta educación en su casa dirigida por su madre, estudió después magisterio, estuvo en contacto con maestras feministas moderadas como Suceso Luengo y Teresa Aspiazu, y se halló inmersa en el universo institucionista desde los 18 años, tras su llegada a Madrid. Incluso antes, pues también en Málaga había frecuentado grupos afines a la Institución, como la Sociedad Malagueña de Ciencias (fundada en 1872), y además uno de los mejores amigos de su familia fue desde muy temprano Alberto Jiménez Fraud, director desde su fundación de la Residencia de Estudiantes. Como indica Gutiérrez Vega, Kent gestó en esos ambientes "un neo-elitismo burgués, marcadamente liberal que conformó su pensamiento" (Capel Martínez, 1982, pp. 519520; Gutiérrez Vega, 2001, p. 28). Las elecciones de 1933 parecieron dar la razón a los contrarios al sufragio femenino, pues ganaron las derechas. Pero dos años después lo hicieron las izquierdas. Es imposible que en unos pocos meses la mujer española se educara de forma tan intensa en las bondades de la República (de la que al parecer era enemiga mortal) como para dar la vuelta radical a la vida política del país. Parece más razonable pensar que todo era más complicado y no dependía tan crucialmente del voto femenino. No obstante, Campoamor cargó con este sambenito el resto de su vida. Fue acusada por toda la izquierda de ser la única culpable de la victoria de las derechas en 1933. Su vida política declinó: no fue admitida en la Izquierda Republicana de Casares Quiroga ni en ninguna otra agrupación del Frente Popular. En junio de 1936, un mes antes de la sublevación militar, escribió El voto femenino y yo: mi pecado mortal (1936/2006).

De cualquier manera, lo que el tema del sufragio revela es la fuerza y extensión de una mentalidad compartida sobre la mujer: su incapacidad de aportar algo a la vida de la nación debido a sus notables carencias. Cuestión totalmente errónea, como ya se estaba encargando de demostrar la vida práctica en varios ámbitos profesionales.

\subsection{Mujeres científicas en la vida profesional}

Porque Victoria Kent y Clara Campoamor, universitarias, abogadas y políticas, no fueron las únicas mujeres que destacaron en los años treinta. Otra universitaria, licenciada en Medicina, ocupó un puesto político durante la República: Amparo Poch y Gascón (1902-1968), propagandista libertaria, especializada en Pediatría y Puericultura, defensora del sexo lúdico, que fue nombrada Directora General de Asistencia Social una vez comenzada la guerra civil. Se dedicó a la reinserción de las prostitutas y a poner en marcha las granjas escuelas para niños. Ambos proyectos tuvieron una vigencia limitada, pues fueron superados por la dinámica de la guerra y en especial por la defenestración del gobierno y sus cuatro ministros anarquistas en mayo de 1937. Se exilió en 1939 (Franco, 2007, p. 196; Martínez et al., 2000, pp. 636-639).

Pero quizá lo más relevante de los años treinta sea la aportación femenina al campo de las ciencias experimentales. Conocemos la identidad y contribuciones de 36 mujeres que entre 1931 y 1936 trabajaron en el Instituto Nacional de Física y Química, una de las instituciones creadas por la Junta para 
Ampliación de Estudios. Esas 36 mujeres, de un total de 158 personas, suponían el 22\% de los investigadores del Instituto: una cifra nada despreciable. Las científicas que allí desarrollaron su carrera profesional procedían de familias de clase media, con padres de profesión liberal; once de ellas eran antiguas alumnas del Instituto-Escuela; ocho fueron becadas para investigar en el extranjero; y al menos nueve de ellas lograron terminar el doctorado. Sus trabajos se centraron en Espectroscopia y QuímicaFísica. De esas 36 mujeres, 18 produjeron un total de 63 artículos científicos, pues no todas Ilegaron a publicar. Seis de ellas destacan sobre las demás, ya que fueron autoras de las tres cuartas partes de la literatura científica citada: Jenara Vicenta Arnal, Teresa Toral, Piedad de la Cierva, Dorotea Barnés, Teresa Salazar y Carlota Rodríguez.

De Jenara Vicenta Arnal ya hablamos anteriormente, pues comenzó su carrera profesional en los años 20. Hay que añadir que fue la mujer que más publicó del Instituto Nacional de Física y Química, once artículos a lo largo de estos años. En 1931 logró ser catedrática interina de Física y Química en el Instituto Nacional Femenino de Barcelona. En 1932 fue becaria de la Junta para Ampliación de Estudios y pasó seis meses en Alemania y Suiza investigando en temas de electroquímica y físico-química. En 1932-33 obtuvo por concurso la cátedra del Instituto Velázquez de Madrid (Magallón Portolés, 1999, pp. 223-235, p. 307).

Dorotea Barnés González se doctoró en 1931 con una tesis sobre la cistina. En 1931-32 empezó a trabajar en la sección de Espectroscopia del Instituto Nacional de Física y Química, concretamente en Raman, y viajó a Graz para trabajar un tiempo con el científico europeo que más había investigado sobre ello. Publicó cinco artículos y fue la introductora de la espectroscopia Raman en España. En 193334 , además de seguir con sus investigaciones, logró la cátedra de Física y Química en el Instituto Lope de Vega de Madrid. El matrimonio le apartó de su trabajo profesional antes de estallar la guerra civil. Hubo de salir de España con su marido y su hija de pocos meses. En Francia trabajó en un Liceo. A su vuelta a España ocultó tanto sus apellidos como sus grados y méritos académicos (Laporta et al., 1987, pp. 165-166; Magallón Portolés, 1999, pp. 278-290).

Teresa Toral, nacida en Madrid el 20 de mayo de 1911 , se licenció en Química con sobresaliente y premio extraordinario en 1933. A partir de ese momento fue colaboradora del Instituto Nacional de Física y Química, en la sección de Químicas. También fue ayudante de prácticas en la Facultad de Ciencias de la Universidad de Madrid. En 1939 fue detenida en la capital y encarcelada en la prisión de Ventas.

Piedad de la Cierva Viudes (1913-2007) se licenció en Químicas en Murcia en 1932 con Premio Extraordinario. En 1934 obtuvo el doctorado. Desde 1932 hasta 1936 trabajó en el Instituto Nacional de Física y Química en la sección de rayos X. Publicó siete artículos científicos durante su estancia en este organismo. En 1936 recibió una pensión de la Junta para Ampliación de Estudios para dedicarse a la física teórica en Copenhague.

Carlota Rodríguez de Robles Junquera (1907) se licenció en Química con premio extraordinario en 1933, en la Universidad de Madrid y logró el doctorado en 1936. En esos años publicó cuatro artículos científicos, mientras investigaba en la sección de Química-Física en el Instituto Nacional de Física y Química. Por su parte, Teresa Salazar Bermúdez ya era doctora, con premio extraordinario, en 1931. Trabajó en el Instituto Nacional de Física y Química y su trayectoria estuvo unida a la revisión de pesos atómicos. Con este fin, disfrutó una pensión de la Junta para Ampliación de Estudios y pasó unos meses en París para profundizar en el núcleo atómico. Publicó cinco artículos científicos y colaboró estrechamente con el Dr. Moles, con quien realizó algunas de las publicaciones aludidas. Entre 1930 y 1933 fue profesora auxiliar de la Facultad de Ciencias de Madrid (Ballarín y Ortiz, 1998, p. 59; Magallón Portolés, 1999, pp. 213214, pp. 234-235, p. 314, pp. 337-339).

Con independencia de las anteriores, pues no trabajó en el Instituto Nacional de Física y Química, tenemos el caso de Isabel Torres, que había realizado su tesis doctoral en Nutrición en la Casa de Salud de Valdecilla. En los años treinta se convirtió en una importante promesa de la investigación española. En 1933 obtuvo una beca post doctoral para trabajar sobre la estructura de las vitaminas en el Instituto de Patología Médica de Madrid, con José Collazo. En 1934 recibió una pensión de la JAE que le permitiría seguir con ese tema en Heidelberg. Pero cambió de destino y se dirigió a Munich, donde estudió la estructura química de la vitamina K. Renovó un año más y estando allí sobrevino la guerra civil. Tenía una propuesta del Dr. Marañón para regresar en 1937 con un puesto de investigadora en el Hospital Central. Pero en 1939 sus colegas y maestros estaban en el exilio y no tuvo posibilidad de continuar con su carrera. 


\subsection{Carreras profesionales en las humanidades y la enseñanza}

La presencia de un porcentaje no pequeño de mujeres en el mundo científico y la brillantez de las carreras brevemente reseñadas aquí, hace pensar que el movimiento de incorporación a la vida profesional empezaba a tomar ciertas dimensiones. De hecho, si nos fijamos en las becas que ofreció la Junta para Ampliación de Estudios, desde su creación hasta la guerra civil, vemos que en los años treinta aumenta de manera considerable el número de mujeres que reciben una pensión. Entre 1908 y 1919, la Junta concedió 645 becas, 27 de ellas a mujeres, lo que supone un 4\%; para el período 1920-1929 las cifras son 539 ayudas, 41 de ellas disfrutadas por mujeres, y un porcentaje del 8\%; por fin, en el corto segmento 1930-1934, se concedieron 410 becas por parte de la Junta, de las cuales 53 fueron destinadas a mujeres y el porcentaje se elevó hasta el 13\% (Magallón Portolés, 1999, p. 142; Capel Martínez, 1982, pp. 569-581). Cabe suponer que estos números hubieran seguido su tendencia natural al alza de no haber sobrevenido la contienda.

De estas 53 becas de los años treinta destinadas a mujeres, la mayoría, 35, fueron disfrutadas por maestras de Normales, directoras de Primera Enseñanza y directoras de grupos escolares, así como por mujeres que practicaban actividades artísticas: canto, pintura, escenografía. Es decir, no eran licenciadas universitarias. Las científicas se llevaron 18 de esas 53 pensiones, lo cual supone una proporción mucho menor, aunque se puede afirmar también que, en aquel período, de ocho ayudas concedidas para investigación en ciencias experimentales, una de ellas era disfrutada por una mujer (Magallón, 1999, 160-161). No es una mala proporción.

Hubo pensiones igualmente para licenciadas en Humanidades. En 1930, Adela Trepat, catedrática del Instituto de Reus pasó catorce meses en Alemania estudiando Epigrafía latina. En 1932, Amanda López Meneses, licenciada en Filosofía y Letras estuvo dos meses en Francia realizando 'investigación histórica', sin más detalles. También en 1932 Teresa Andrés Zamora, del cuerpo de Archiveros, Bibliotecarios y Arqueólogos, pasó once meses en Alemania realizando estudios de esta última especialidad. En 1934 nos encontramos con María Encarnación Cabré, que pasa igualmente once meses entre Francia, Suiza y Alemania realizando estudios de Etnografía y Prehistoria. Era Licenciada en Filosofía y Letras (Capel Martínez, 1982, pp. 576-581).
Igual que las becas logradas por las mujeres científicas parecen estar relacionadas con los intereses de sus equipos o con sus propias tesis doctorales, las de las maestras o licenciadas en Letras dan la impresión de ir dirigidas a ampliar conocimientos o a adquirir técnicas pedagógicas, pero no a realizar investigación académica.

Existen mujeres que trabajaron en el Centro de Estudios Históricos, creado por la Junta para Ampliación de Estudios, pero no estamos en condiciones de asegurar que fueran licenciadas, ni que sus trabajos estuvieran dirigidos a enriquecer la investigación de un equipo o a realizar sus propias tesis doctorales. Podemos citar a María Teresa Casares, Consuelo Gutiérrez del Arroyo, María Brey y Carmen Díaz Caamaño, a quienes encontramos en 1932 trabajando en el Instituto de Estudios Medievales, dirigido por Sánchez Albornoz, en la subsección de Diplomas. Los nombres de Pilar Loscertales y Ana Pardo aparecen en la sub-sección de Fueros. En la misma fecha, María Victoria González Mateos trabajaba como becaria en el Fichero de Arte Antiguo, con Ricardo de Orueta y Sánchez Cantón. Sacaron a la luz dos volúmenes de Monumentos Españoles en 1932. Por último, hay que referirse a María Millás, que en 1933 publicó "Contratos de judíos y moriscos del reino de Navarra", en el Anuario de Historia del Derecho Español, una revista del Centro de Estudios Históricos (López Sánchez, 2006, p. 113, p. 119, p. 408).

Por los años 30 siguieron también con actividad profesional mujeres que ya contaban con cierta trayectoria, como María Sánchez Arbós que en 1933 obtuvo la primera plaza en las oposiciones a directora de grupo escolar, y que en 1934 fue nombrada para uno de nueva creación, experimental en buena medida, llamado "Francisco Giner de los Ríos". También podemos referirnos a María Moliner, que a partir de 1931 trabajó en la Biblioteca del Ministerio de Hacienda en Valencia, dio clases en la Escuela Cossío, seguidora de los métodos y la mente del Instituto-Escuela de Madrid; y a partir de septiembre de1936 pasó a dirigir la Biblioteca de la Universidad de Valencia (Jiménez-Landi, 1996, pp. 496-498; Martínez et al., 2000, pp. 598-599).

Hubo otras muchas mujeres anónimas que desarrollaron sus carreras en el mundo profesional. Conocemos, por ejemplo, el dato de profesoras de los Institutos de Enseñanza Media, puesto al que se llegaba por oposición y con una licenciatura previa: en 1930-31 eran 144; en 1931-32 bajaron a 126; pero en el curso siguiente, 1932-33, casi se doblaron: hubo 236 mujeres que impartieron enseñanzas variadas en los establecimientos oficiales españoles de Enseñanza Media (Merino Hernández, 2003, p. 419). 
Hay que añadir, por último, que la Universidad en sí misma fue una de las instituciones que más tarde abrieron sus puertas a la carrera profesional de la mujer. El personal docente femenino fue muy escaso y estuvo siempre en puestos auxiliares. En 1932-33 Vázquez Ramil ha contado 64 mujeres en las Facultades españolas: dieciséis en Ciencias, una en Derecho, nueve en Farmacia, veintitrés en Filosofía y quince en Medicina (Vázquez Ramil, 2001, p. 125). En Estados Unidos, en 1930, casi un tercio del profesorado femenino universitario eran mujeres (el 27\%) (Salomon, 1985, p. 133).

\subsection{Las variedades profesionales de las licenciadas en Derecho}

Entre las mujeres universitarias que desarrollaron carreras profesionales de prestigio en los años 30 en ámbitos ajenos a la ciencia, hay que citar a Josefina Carabias, licenciada en Derecho y periodista de enorme popularidad en el Madrid republicano. Comenzó en 1931 su trabajo en la prensa. Fue corresponsal parlamentaria del diario $\mathrm{La}$ Voz, la única en ese momento de un periódico de información general. Colaboró en Crónica y Mundo Gráfico, semanarios; y en otros diarios como Ahora y en otras revistas como Estampa. En 1934 se incorporó a Unión Radio, convirtiéndose en la primera locutora de noticias en España. Además en 1932 había aprobado las oposiciones para Registradora de la Propiedad, pues durante la República la mujer sí pudo acceder a este tipo de exámenes. Se casó en 1936 y salió al exilio al estallar la guerra civil, no pudiendo regresar hasta 1943 (Martínez et al., 2000, pp. 460-461; Mangini, 2001, pp. 193-194).

María Lacunza, otra licenciada en Derecho fue la primera navarra que obtuvo este título y también la primera en colegiarse en Pamplona (1927). En 1932, en Madrid, ingresó como funcionaria en la Administración del Estado, ocupando una plaza de auxiliar interino en el Ministerio de Agricultura, Industria y Comercio, en la Inspección General de los servicios social-agrarios. Fue secretaria de una Comisión organizada en 1932 para estudiar la reforma agraria en diversos países, y se le expidió pasaporte para viajar al extranjero. No perteneció a ningún partido y por ello fue sospechosa para la República una vez estallada la guerra civil y depurada en 1940 por el régimen de Franco (Diario de Navarra, 20 de noviembre de 2005, p. 64).

Podemos concluir que iba avanzando, aunque lentamente, la presencia de la mujer en la vida profesional. Sin embargo, la mayor parte de las carreras quedaban cortadas por el matrimonio. Nadie entendía, ni siquiera la mayor parte de las mujeres, que las cosas pudieran ser de otra manera. Dorotea Barnés dejó sus investigaciones cuando se casó y era una de las científicas más brillantes del momento. Lo mismo cabe decir de otras, como Teresa Zorraquino, que tras leer su tesis en 1930 en Químicas, contrajo matrimonio y abandonó la actividad investigadora. Su marido no le permitió seguir. Él también era químico y llegó a ser catedrático de la Universidad de Zaragoza en la década de los sesenta. El trabajo de la mujer fuera de casa, según confesión de la propia María Teresa Zorraquino, suponía un menoscabo para el hombre. Enriqueta Castejón, licenciada en Farmacia y Química por la Universidad de Zaragoza, sufrió la misma suerte pues abandonó las clases que impartía en la Universidad cuando se casó con un catedrático de Química de la misma Facultad. Sin embargo regentó hasta su jubilación una farmacia propia en la capital aragonesa, compra que hizo su padre para ella en los años veinte (Magallón Portolés, 1999, pp. 106-109).

\subsection{Carreras profesionales en Europa y América}

Cuando la mujer española, en los años de la Segunda República, estaba todavía asomando la cabeza a la vida profesional, otros países del entorno occidental le llevaban ventaja, en algún caso notable. En primer lugar, los Estados Unidos. Muchas de las cuestiones que en España no tenían vuelta atrás (el matrimonio lo cortaba todo, o casi todo) eran asuntos que ya estaban abiertamente planteados al otro lado del Atlántico y para los cuales se buscaban soluciones.

El tema fue tratado por dos prestigiosos órganos periodísticos del momento: en 1933 se hizo eco del nuevo fenómeno el New York Times y en 1936 la revista Fortune. Las mujeres entrevistadas por ambas publicaciones mostraban el mismo deseo de casarse que de trabajar y pensaban que familia y profesión eran compatibles, al menos si se tenía clara la vocación. Se decantaban por horarios flexibles y por ocupaciones que lo hicieran factible, como escritora o decoradora. Pero también había muchachas que en esas entrevistas declaraban sentirse incapaces de compaginar trabajo y familia, y animaban a las demás a dejar la profesión. El debate, pues, estaba abierto. En términos globales, el número de casadas que afrontaban un trabajo fue creciendo en Estados Unidos en el periodo de entreguerras y aumentó con la Segunda Guerra Mundial: en 1945 un cuarto de las mujeres casadas trabajaban y suponían un tercio de la población femenina activa (Salomon, 1985, pp. 172-185). 
En Gran Bretaña, en la década de los 30, parecía que la única salida para una mujer con carrera universitaria era la enseñanza, y a ella se dedicaba la mayoría de las graduadas: en 1939 eran profesoras de secundaria entre la mitad y las tres cuartas partes de las licenciadas. Dyhouse ha hecho notar que la formación para la enseñanza secundaria era más popular y se tomaba mucho más en serio entre las mujeres que entre los hombres. Esta misma autora afirma también que en Gran Bretaña, todavía en los años 30, si la mujer optaba por la carrera académica, quedaba fuera una vez que contraía matrimonio. No obstante, en esa década funcionó con eficacia, siguiendo la tradición asociacionista anglosajona, The British Federation of University Women, una red de mujeres que desempeñaba su tarea profesional en puestos universitarios. En 1932 contaba con 25 agrupaciones locales, 3.500 socias y su propia revista (Dyhouse, 1995, pp. 18-19, p. 134-141, p. 170). Ello demuestra que no eran pocas y que tenían sus propios objetivos.

Parece que el movimiento de acceso de las mujeres a la educación superior, y después a la vida profesional, nacía de la base tanto en los Estados Unidos como en Gran Bretaña; y que se autoalimentaba o se dinamizaba por sí mismo, con iniciativa propia, sin detenerse ante la fuerza de la mentalidad social: ellas eran quienes la configuraban, las que se empeñaban constantemente en estar en el origen de los cambios.

\section{A MODO DE CONCLUSIÓN}

Las mujeres españolas durante los años veinte y treinta se empeñaron por si mismas en estudiar en la Universidad y en desarrollar carreras profesionales al mismo nivel que el hombre. No fueron muchas pero puede afirmarse que su contribución no fue pe- queña: alcanzaron puestos políticos e hicieron avanzar al país (por ejemplo con la introducción del voto femenino); estudiaron ámbitos nuevos en sus investigaciones científicas e introdujeron en España técnicas y aportaciones hasta entonces desconocidas. A algunas les debemos importantes contribuciones en el ámbito de la filología, como a María Goyri y a María Moliner. Fueron muchas las que enseñaron a otras mujeres en los Institutos de Enseñanza Media, fomentando entre las niñas y adolescentes el ejemplo de la mujer instruida y moderna. Todas contribuyeron a que fuera cambiando la mentalidad.

Esta se caracterizaba por una atrofia de la razón que se paraba ante los pretendidos obstáculos insalvables (matrimonio), o los prejuicios simplistas (falta de inteligencia, conservadurismo social) para impedir el acceso de las mujeres al ejercicio de sus derechos o a una carrera profesional. Cuando no se trataba pura y simplemente del espanto del varón ante la presencia femenina en la escena pública.

Pero se trataba de una mentalidad sin futuro. Los países más avanzados hacía ya tiempo que debatían estas cuestiones y no faltaban propuestas para que la mujer siguiera avanzando en sus aspiraciones. No faltaban tampoco los obstáculos, pero por la vía de los hechos las mujeres con educación superior se imponían en los distintos ámbitos profesionales. Era cuestión de tiempo que llegara a todos.

La dinámica española, más atrasada que la norteamericana o la británica, no era, sin embargo, menos ambiciosa: Victoria Kent fue la primera mujer del mundo que ocupó un alto cargo político. Podemos concluir que, de no haber sobrevenido la guerra civil, el acceso femenino a la educación superior y al ejercicio profesional hubiera sido mucho más rápido en España.

\section{BIBLIOGRAFÍA}

Ballarín, P. y Ortiz, T. (eds.). (1998). La mujer en Andalucía. Encuentro Interdisciplinar de Estudios de la Mujer. Granada: Universidad de Granada.

Barrera Peña, M. L. y López Peña, A. (1983). Sociología de la Mujer en la Universidad: Análisis histórico-comparativo. Galicia-España 1900-1981. Santiago de Compostela: Universidad de Santiago de Compostela.

Campoamor, C. (1936/2006). El voto femenino y yo: mi pecado mortal. Madrid: Horas y Horas.
Capel Martínez, R. M. (1982). El trabajo y la educación de la mujer en España (19001936). Madrid: Ministerio de Cultura, Instituto de la Mujer.

Cuesta Burillo, J. (ed.) (2003). Historia de las Mujeres en España. Siglo XX. Madrid: Instituto de la Mujer.

Dyhouse, C. (1995). No distinction of sex? Women in British Universities 1870-1939. London: University College London.

Ezquerra, R. (1926). La penetración de la mujer española en la Universidad. I. Renovación Social, 44, pp. 490-494.
Ezquerra, R. (1926b). La penetración de la mujer española en la Universidad. II. Renovación Social, 45, pp. 532-536.

Ezquerra, R. (1926c). La penetración de la mujer española en la Universidad. III. Renovación Social, 46, pp. 629-632.

Fagoaga, C. y Saavedra, P. (2007). Clara Campoamor, una sufragista española. Madrid: Instituto de la Mujer.

Flecha, C. y Torres, I. (eds.) (1993). La mujer, nueva realidad, respuestas nuevas. Madrid: Narcea. 
Flecha, C. (1996). Las primeras universitarias en España: 1872-1910. Madrid: Narcea.

Flecha, C. (1998). Textos y Documentos sobre la Educación de las Mujeres. Sevilla: Kronos.

Franco, F. J. (2007). Mujeres de la España Republicana. Cartagena (Murcia): Aglaya.

Garrido, E. (ed). (1997). Historia de las mujeres en España. Madrid: Síntesis.

Gutiérrez Vega, Z. (2001). Victoria Kent. Una vida al servicio del humanismo liberal. Málaga: Servicio de Publicaciones de la Universidad de Málaga.

Jiménez-Landi, A. (1996). La Institución Libre de enseñanza y su ambiente (Tomo IV: Periodo de expansión influyente). Madrid: Ministerio de Educación y Cultura.

Laffitte, M. (1964). La mujer en España. Cien años de su historia 1860-1960. Madrid: Aguilar.

Laporta, F. J., Ruiz Miguel, A., Zapatero, V. y Solana, J. (1987). Los orígenes culturales de la Junta para Ampliación de Estudios. Arbor, 493, pp. 17-87.

Laporta, F. J., Ruiz Miguel, A., Zapatero, V. y Solana, J. (1987). Los orígenes culturales de la Junta para Ampliación de Estudios (2a parte). Arbor, 499-500, pp. 9-138.
López Sánchez, J. M. (2006). Heterodoxos españoles. El Centro de Estudios Históricos 1910-1936. Madrid: Consejo Superior de Investigaciones Científicas.

Magallón Portolés, C. (1999). Pioneras españolas en las ciencias: las mujeres del Instituto Nacional de Física y Química. Madrid: Consejo Superior de Investigaciones Científicas.

Maillard, M. L. (1990). Asociación Española de Mujeres Universitarias (1920-1990). Madrid: A.E.M.U.

Mangini, S. (2001). Las modernas de Ma drid. Las grandes intelectuales españolas de la vanguardia. Madrid: Península.

Marset, J. C. (2004). María Zambrano. I. Los años de formación. Sevilla: Fundación José Manuel Lara.

Martínez, C., Pastor, R., Pascua, M. J. y Tavera, S. (2000). Mujeres en la Historia de España. Enciclopedia biográfica. Barcelona: Planeta.

Merino Hernández, R. M. (2003). La educación de las mujeres durante la Segunda República (1931-1939): aproximación cuantitativa. En: Cuesta Burillo, J. (ed.). Historia de las mujeres en España. Madrid: Instituto de la Mujer, pp. 413-435.

Montero, M. (2013). La conquista del espacio público. Mujeres españolas en la universidad (1910-1936). Madrid: Biblioteca Nueva.
Pérez-Villanueva Tovar, I. (1989). Una mujer en el reformismo educativo español. María de Maeztu. Madrid: Universidad Nacional de Educación a Distancia.

Pérez-Villanueva Tovar, I. (1990). La Residencia de Estudiantes: grupo de universitarios y señoritas, Madrid 19101936. Madrid: Ministerio de Educación y Ciencia.

Ribagorda, Á. (2005). Una historia en la penumbra: las intelectuales de la Residencia de Señoritas. Sistema, 188, pp. 45-62.

Rodrigo, A. (1979). Mujeres de España (las silenciadas). Barcelona: Plaza \& Janés.

Salomon, B. M. (1985). In the company of Educated Women. A History of Women and Higher Education in America. New Haven, London: Yale University Press.

Segura Graiño, C. (ed). (1997). La historia de las mujeres en el nuevo paradigma de la Historia. Madrid: Asociación Cultural Al-Mudayna.

Varela, I. (1989). La Universidad de Santiago 1900-1936. Reforma universitaria y conflicto estudiantil. Sada, A Coruña: Ediciós do Castro.

Vázquez Ramil, R. (2001). La Institución Libre de Enseñanza y la Educación de la Mujer en España: La Residencia de Señoritas (1915-1936). Betanzos: LUGAMI Artes Gráficas. 